\title{
Beauty in the complexity of the brain
}

Brains, The Mind as Matter

Marius Kwint and Lucy Shanahan, Curators

Wellcome Collection

London, UK

March 29, 2012 to June 17, 2012

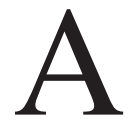

fter I saw this exhibition, I tried to choose which element affected me the most. Was it the photographer's picture of herself in the head brace with the needle going in? Was it the photo of the kid awaiting brain surgery? The letter from a mother donating her child's brain? The video of the top of a head being put back on?

Guest curator Marius Kwint, Senior Lecturer in Visual Culture at the University of Portsmouth, explained that the exhibition was not meant to be a gruesome delight. Rather, it shows through objects what we have done to the brain over centuries It is a timely topic not only because of the Wellcome Centre's earlier popular exhibition on skeletons but also because of the general surge in interest in the interior workings of the body and particularly of the brain, for example, the popularity of writers such as Oliver Sacks and the $B B C$ 's recent airing of Dr. Geoff Bunn's A History of the Brain. The developments in neuroscience in the 1990s have led to the brain being represented through functional magnetic resonance imaging and related imagery in the media, but in a spectacular and somewhat idealized way - what this exhibition tries to do is show the organ to which those images refer. The exhibition is a visual narrative that puts today's neuroscience in a historical and cultural context.

The exhibit is divided into four sections: Measuring/Classifying, Mapping/Modelling, Cutting/Treating and Giving/Taking. It is especially in the third section that you see the violence

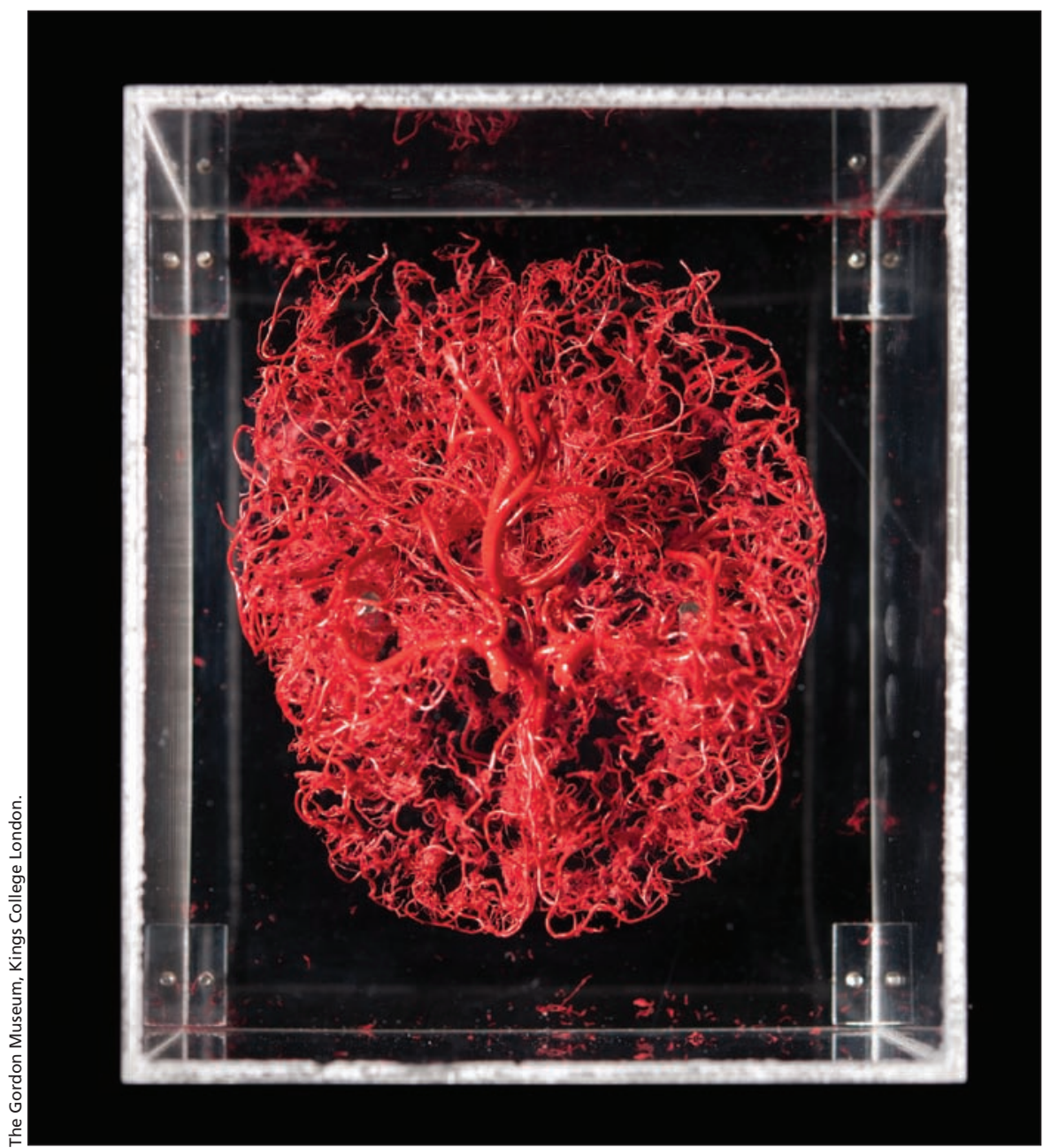

Corrosion cast of brain blood vessels, plastic.

of medicine. Marius Kwint again: "the study of the brain has often had a subtext of violence, since finding out about its workings has depended on damage to particular areas of its otherwise inscrutable substance. And of course surgery is a kind of sanctioned and controlled (and hopefully beneficial) violence." Tools for trepanning are carefully laid out near a Bronze Age skull with three neat holes in it. A 2012 video shows two people meticulously slicing "fixed" brains at the Brain Bank of the Imperial College of London. There is also a display section on electroconvulsive therapy, with the equipment artistically arranged. Beside the case is a video loop of a woman calmly submitting to shock treatment. Visitors may find her convulsions difficult to watch.

Among drawings and replicas of the human brain, and tools used on the brain, there are real brains. As Kwint explained, "what makes this collection unique is that it has a human tissue licence that enables us to show these specimens, including very modern ones." Thus we can see a slice of Einstein's brain and think about the dubious 
science of looking for genius in tissue. Helen Gardener, an American women's suffragist who died in 1925, argued that a female brain was not demonstrably different from a man's. Her brain is on display beside a murderer's. Others include diseased brains in jars, and a brain with a bullet lodged in it.

In counterpoint to the brain samples and tools are the drawings and artwork throughout, some of it commissioned for the exhibit. Ania Dabrowska's photo series, "After I'm Gone," includes a photograph of a headrest

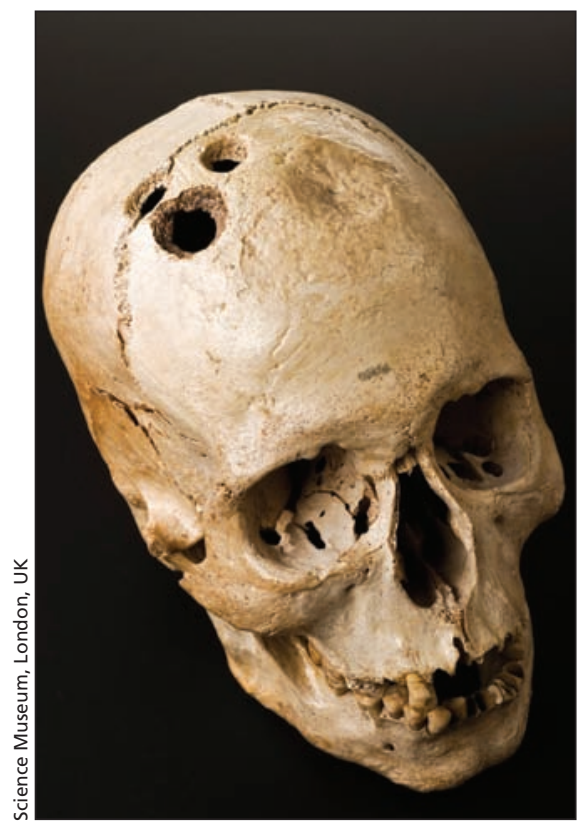

Trepanned Bronze Age skull from Jericho, Palestine, 2200-2000 BC. (with three indents for different sizes) that holds the head steady while the brain is removed. In others, medicine and art come together, as in surgeon Harvey Cushing's detailed drawing of the head opened to expose the brain's gunshot wound. There are also some interesting self portraits by patients contemplating the post-mortem removal of their brains.

What affected me the most was the extraordinarily beautiful corrosion cast of the blood vessels in the brain. To see the brain inside out, as it were. Made by injecting resin into the vascular system and then corroding away the surrounding tissue, the process produces a hardened cast of the brain's blood vessels. The result is something that looks both delicate and like a tree (dendritic).

The first three sections of the exhibit reveal much that is not fine in the art of medicine: phrenology, anthropometry, lack of patient consent, the Nazi's Aktion T4 program and collection of brains. That is the context we are asked to remember as neuroscience moves forward in the study of the brain and its ailments. The fourth section, Giving/Taking, helps us consider these ethical issues by concluding with good practice. Here we find three patients who talk about donating their brains to science after they die in order to contribute to the study of Alzheimer disease.

Absent from the exhibit were recent discoveries about the brain, such as

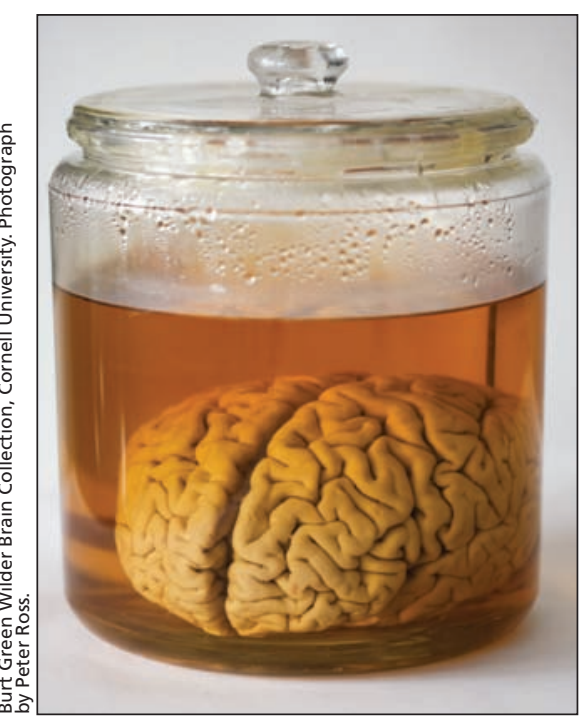

The brain of Helen H. Gardener.

brain imaging (except for a screen of a brain "purportedly" responding to music). I liked that the exhibition was not dependent on oversized wall plaques of text and had a good mix of artefact and video. And I liked it for showing me the brain as beautiful.

\section{Debra Martens MA \\ Writer}

London, UK

For more information see www.wellcomecollection.org/brains or play a free online game at www.wellcomecollection.org/axon

CMAJ 2012. DOI:10.1503/cmaj.120593 